\title{
Challenges and Potential of Teaching Engineering Students in Developing Countries Using New Trends and Methodologies
}

Dr. Adeel Khalid, Southern Polytechnic College of Engineering \& Engineering Technology

Adeel Khalid, Ph.D. Associate Professor Systems Engineering Office: 678-915-7241

Dr. Salahuddin Qazi, State University of New York, Institute of Tech.

Sala Qazi holds a Ph.D., degree in electrical engineering and is a Professor Emeritus at the State University of New York Institute of Technology (SUNYIT), Utica, New York. Prior to becoming an emeritus, he spent a year completing a project on developing instructional material for an NSF funded project on "Visualization and Manipulation of Nanoscale Components using Atomic Force Microscopy. During his tenure at SUNYIT, he was chairman of the EET department, coordinator of photonics program and Director of the Master of Science program in advanced technology, which he helped to develop. 


\title{
Challenges and Potential of Teaching Engineering Students in Developing Countries Using New Trends and Methodologies
}

\begin{abstract}
:
The purpose of our paper is to review the challenges and potential of educating engineering students using traditional methods of learning in the developing countries. This will be compared to new methods of learning where the objective is not only knowledge acquisition but also knowledge creation such as project and problem based learning. The potential implies that an effective engineering education process in the developing countries can assure a global supply of well-prepared engineering graduates needed to enhance focus on innovation, entrepreneurship and job creation and fill the shortage of quality engineers.
\end{abstract}

The traditional system of learning in developing countries such as Pakistan is based predominately on memorization with very little independent learning through self-study or problem solving by collaborative or team work. Students rarely challenge the integrity of instruction by the instructors leading to the lack of interactive relations vital to creativity and innovation. The curriculum is highly structured and there is little room to take liberal arts or interdisciplinary courses to broaden their education. Not enough emphasis is placed on professional competencies which are important for today's engineers competing in a global market. Accreditation as a relatively new phenomenon in the developing countries face the challenge of ensuring quality based on standards while also facilitating innovations in education. There is a lack of resources for upgrading laboratories, shortage of trained teachers to teach effectively and make the course curriculum relevant to the need of the country. Students' learning is further compounded with new developments in electronic media which are leading to enormous challenges for teachers with regards to the role digital devices can and should play in the learning process. Despite these challenges, the engineering institutions in Pakistan are attracting an increasing number of highly competent applicants for a limited number of seats.

The authors discuss various challenges in educating engineering students accustomed to traditional methods of teaching and assessing in the structured engineering curriculum used in some developing countries and identify potential areas of change. The authors also give recommendations, based on new trends and methodologies to meet the challenges in Pakistani engineering institutions that are currently seeing tremendous increase in student enrollment.

\subsection{Introduction}

A recent report by UNESCO revealed that "an acute and growing shortage of engineers has become a threat to global development." Many countries are seeing decline in the enrollment of young people in engineering discipline despite the urgent need of creative solutions to address challenges of poverty, environment, energy, security and socio economic development among other issues. In Germany, the engineering students enrolled in the engineering institutions have dropped to half in ten years. In Netherland, Norway, Japan, and Republic of Korea enrollment has reduced between 5 to 10\% since late 1990s. According to the German Institute of Economics, the country currently needs 117,000 engineers, scientists, IT experts and technicians. U.K is also faced with a chronic shortage of science graduates and especially engineers, where 
several industries are struggling with a shortage of engineers in the area of power generation, aerospace and manufacturing. Sub-Saharan Africa alone needs 2.5 million new engineers and technicians if the region was to achieve the UN Millennium Development Goal of improved access to clean water and sanitation [1].

The number of engineering graduates enrolled in Asian countries and their population trend shows that the worldwide engineering workforce in the next generation will be largely Asian. The enrollment in absolute term of engineering students in South Africa has increased by 60\% between 2000 and 2006 [2]. In a flat world where corporations with their engineers are moving from one continent to another either to undertake projects or to make use of their technical workforce, the profession of engineering is relying on a global workforce. Many high technology corporations in the developed world have extensive global linkages and export engineering services by employing a global workforce. The future engineer will be challenged to address some of the world's technological, environmental and social problems such as conserving energy resources, resolving the world's food and water crisis, curing diseases and improving global safety and security. In addition to these challenges engineers and engineering education is also faced with knowledge creation and knowledge transfer whereby countries around the world are moving toward developing knowledge based economies. In other words knowledge, in addition to capital, labor and land is becoming a primary factor of production leading to reduced cost, improved quality and better response to consumer needs [3]. These challenges are further compounded by new modes of communications and interconnectedness, knowledge production and an ever changing technology and information landscape. As a result it is important to understand as to how information technology can best be used to improve and enhance learning and teaching to educate engineering students by departing from the traditional ways. The engineers of the future not only need to be knowledgeable in their own disciplines, but also need a new set of skills to thrive in a world of complexity, volatility, uncertainty and ambiguity where there will be risks as well as opportunities [4].

To address the above mentioned challenges in engineering education in Asian countries such as Pakistan, where education is based on traditional methods of learning and teaching, new tools and methods need to be developed and employed to impart engineering education. Although new methods and tools may use digital media and information technology for improvement, the education of engineering educators is of paramount importance. Number of tools, methodologies and pedagogical techniques have been developed and are used to enhance teaching and student learning in different engineering disciplines at various US universities [5]. Such tools are necessary to help improve the standard of engineering education and foster the growth of scholarship of teaching and learning in classroom. These tools and techniques can be easily employed in Pakistani engineering institutions without much cost.

After the introduction in section 1, section 2 deals with the challenges of teaching and learning in Pakistan which is predominately based on the traditional system of learning and teaching. Section 3 discusses the challenges of trends and methodologies where learning may be compounded with new developments in electronic media. Sections 4 and 5 discuss the importance of communications, ethics and accreditation which are important to have in a program competing in a global market. Section 6 provides suggestions, based on new trends and 
methodologies to meet the challenges in Pakistani engineering institutions having tremendous increase in student enrollment. Section 7 summarizes the key points presented in the paper.

\subsection{Challenges of Teaching and Learning}

Several differences can be identified between the educational environments of developing and industrialized countries such as structural, cultural and social. Structurally, the engineering education system in Pakistan can be broadly divided into state supported institutions and private institutions. As is normal, the tuition for state-supported institutions is much lower as compared to the private institutions; and hence admission to these state-supported institutions is fierce. Students admitted to the state-supported schools are highly accomplished and very well prepared at least as evidenced by the scores achieved in the 12th grade examinations. However, the compensation structure for the faculty of state supported schools is not competitive. More recently, the Higher Education Commission (HEC) has instituted a 'tenure-track' option with competitive compensations associated with a competitive peer-review process. However, this 'two-track' system is a cause of concern. The engineering institutions are faced with a similar dilemma as its counterparts in the industrialized world. Should the institutions and the faculty focus on research and relegate undergraduate engineering to a perfunctory activity? Furthermore, faculty compensation based on the two-track system complicates the issue even more. The Pakistan Engineering Council (PEC) is the statutory body with one of its functions being the accreditation of engineering programs [6], while the Higher Education Commission is the national institutional accreditation body. Typically the curriculum for engineering programs follows a rigid format with little flexibility to accommodate individual interests.

Furthermore, barring a few elite engineering institutions, most state supported universities have challenges of resources that include infrastructure as well as laboratories. The academic and supporting resources at these institutions are not commensurate with the large student populations. While in the industrialized nations, the role of engineering faculty as facilitators of learning, and pedagogies such as active-learning are gaining acceptance as evidenced by the growing number of engineering education academic programs and professional development opportunities for faculty, the engineering education faculty and administrators in developing countries have not fully recognized the changing landscape. The social and cultural characteristics of these developing countries also play an important role in the acceptance and implementation of modern pedagogical approaches in the classroom. In the industrialized countries, the engineering classroom is challenged by two factors: i.e. student preparation, and student engagement. Several dimensions of student engagement have been identified in research on student engagement and academic success [7, 8, and 9]. It has been reported [10] that institutional policies and practices influence student engagement. Flexibility in engineering curriculum, financial ability to move between majors, and social and cultural aspects of industrialized countries can impact student engagement. It is more probable that engineering students are a captive audience in the classrooms of developing countries resulting from economic and cultural constraints. This engagement however may be superficial and not cognitive. It may not necessarily result in more robust learning; and, it certainly does not provide a motivating reason to faculty for pedagogical innovations aimed at increasing student engagement that would address its multiple dimensions. The continued poor performance of US

students in math and science as documented in the Program for International Students 
Assessment (PISA) in comparison to other countries of Organization of Economic Cooperation and Development (OECD) has been recognized at the highest policy levels [11] and has resulted in several programs by the National Science Foundation to improve the math and science preparation of K-12 students in the US. Extensive research is therefore being undertaken to address the lack of math and science skills as they are affecting the performance of US students in the engineering fields $[12,13$, and 14]. On the other hand, students admitted to the engineering programs in developing countries like Pakistan are considered very well prepared in math skills based on their scores in the 11th and 12th grade exams. While preparation of math skills (procedural knowledge) can be easily gleaned from the performance on these exams, the conceptual understanding and critical thinking associated with problem solving may not be readily determined from these exams. The fluency of students in procedural skills, though an important component, is therefore more often than not considered as 'well-preparedness' in math.

These various structural, social and cultural differences have resulted in an engineering education system that is rigid, lacks incentives for faculty, and does not challenge faculty to experiment with pedagogical innovations to enhance the learning outcomes of the students.

\subsection{Challenges with Technology}

There are challenges associated with implementing the changing trends and methodologies for Pakistani engineering student where learning is compounded with new developments in electronic media. This can lead to enormous challenges for educators in regards to the role digital devices can and should play in the learning process. Faculty members are embracing the use of technology to enhance their classroom teaching today more than ever before. However; in order to effectively use technology in their classroom, they must prepare themselves for some of the challenges they will face in accomplishing this goal. Winnett [6] identifies the following four major issues associated with technology in classroom. Although universal, these challenges are even more exacerbated in developing countries.

- Availability of technology hardware

- Availability of technical assistance

- Software applications

- Time to integrate technology into teaching

The public and private universities in the developing countries are a mixed bag when it comes to the type of computers and other technology devices that are available in the classroom. Some institutions are at par with their western counterparts but more often than not, universities have to scramble to find the required computing resources. There is also the question of how many computers will be available for student and teacher needs. Some public and private institutions have high enrollments with class sizes reaching beyond 100 students. Faculty need to prepare themselves for the possibility that they will have to group students on computers or sequence their usage in multiple sessions and learn other strategies for making the most of the fewest available resources. Technical assistance is also rare in universities. There are limited, if any, technical resource specialists to assist professors. To cope with this shortage, faculty members have to familiarize themselves with simple trouble-shooting technology tasks. Knowing how to 
connect peripheral devices and load software packages are but a few of the many simple little skills that professors should master in order to help themselves and keep the technology tools going in the classroom for an extended period of time. Technology is often not updated for years because of shortage of funds. The available resources need to be cared for and protected.

There is a vast range of application software developed for use by engineers. When the computing resources are shared, and a large number of software packages are loaded, it can slow down the performance of the machines. These software also require some time to master. A possible solution to the problem is the use of multi-disciplinary software that could be used, with some limitations, in lieu of more advanced discipline specific software. When the institutions have the hardware, trouble shooting skills, and the knowledge of how to use the software, it still takes time and experience to effectively integrate the technology into teaching. While the faculty members are developing the skills associated with becoming good teachers, they need to bring their technology integration skills right along. Students learn better, and teaching becomes more effective when the technology is planned right into the lessons. To train engineers of the future, faculty members need to be technology advocates.

In the developing world, there are many reasons for the lack of deeper knowledge of technology integration by faculty members. These include but are not limited by teacher apathy, budget limitations, lack of leadership, and lack of availability of training. Teachers' knowledge of the engineering software application is limited, which consequently limits the meaningful learning experience in the classroom. This process needs direction and support and must be a collaborative effort using the combined knowledge base of the faculty, administrators and technology facilitators [8]. The evolving technology is also creating other challenges for the teachers as they struggle to keep up with the speed of technology change. Professors today need to separate themselves from the past and accept technology as an integral part of the education of students in the $21^{\text {st }}$ century - so these students are capable to compete on the global level. With the ubiquitous computing resources exploding and availability of ideas, faculty members must embrace the accessibility of information on the World Wide Web. Professors need to become more responsive to the resources available on the internet and its use in the classroom. They need to determine ways to connect the online and offline digital media to curriculum content and to the learning processes. These include ideas of using public shared videos, technical contents and student generated material that can be posted online. When these resources are integrated in classroom sessions, the sessions become interactive and hence enriching. Universities need faculty development model that assists professors in understanding technology as a tool for connecting curriculum content to the learning processes.

\subsection{Educating Socially Competent and Responsible Engineers}

Engineering is not only a craft of using logical models to solve technical problems but engineers also make use of their assumptions for what may or may not be of value within the social circles in relation to which they contrive their solutions and carry out their activities. These social circles can be cross-disciplinary teams within which engineers work or they can be the larger populace for which engineers produce a solution. The complex problems of today's world necessitate engineers to work in collaboration by communicating across the various social domains [17]. The technical solutions that they seek to achieve are often entwined with the 
social and environmental context in which the solution is to be implemented thus engineers find themselves in cultural and ethical predicaments. There has been recognition that educating students for real life engineering practice requires as much focus on students to develop professional competencies such as communication and professional responsibility as the focus on students learning disciplinary technical knowledge $[4,18]$. However efforts in the United States to develop education to bring enough emphasis on professional competencies in engineering programs have been successful to only a limited extent $[19,20]$. There are some engineering programs which have attempted to integrate liberal education with engineering education [21, 22] by engaging students in solving sociotechnical problems. However such programs are mostly peripheral to the more mainstream engineering education [19]. Engineering faculty generally consider disciplinary knowledge as the core of engineering curriculum and are unable to see themselves as having a significant role in facilitating students to develop any competencies besides technical concepts and analytical skills.

The challenge becomes more pronounced in developing countries where engineering education institutions function in their localized contexts while preparing students for the globalized world [23]. Many educational institutions lack the infrastructure and the competent faculty who can effectively support student learning. Developing countries with their limited resources tend to focus more on primary education and health. The development of higher education is low on agenda with research on higher education almost nonexistent in most developing countries. Engineering education in many developing countries is based on a western model [24-26]. Universities in these countries generally engage in a transformational effort in response to changes in the western world. They are not able to develop an emphasis on professional competencies and thus reduce the likelihood of shifting the focus of education from technical knowledge to the development of an engineer for working in complex real life situations. On the other hand the internationalization $[27,28]$ and rapid expansion of higher education $[29,30]$ with liberalization of higher education in many countries has given rise to new opportunities for innovations in higher education. Universities of the developed world are opening branch campuses in the developing world which is changing the higher education scene in those countries. In addition factors that pose pressure against educational change in developed countries, such as established traditions of education and of faculty promotion and tenure processes, are much less of issues in developing countries. New institutions in the developing countries have the potential to attract faculty with an innovative outlook for education, organize education on innovative educational models and establish the institution on a culture of educational innovation.

Addressing developing world's growing population demand for energy, water, food and other such needs is among the engineering grand challenges [31]. Most of these are as much social challenges as they are technical challenges. However developing countries adopt curriculum and models of engineering education from developed world without much regards to the national and regional needs [23] which may require a significantly different worldview for engineering education. The planners of education, who may be interested in implementing an apparently working model of engineering education, neglect that an educational model developed elsewhere may not best serve the local needs. Engineers as solvers of societal problems working in the context of developing world do not just need to be working on solutions requiring high end technologies. Rather developing countries also need engineers who are entrepreneurs that could 
develop and market simple economical solutions addressing basic needs on a large scale. Technology Incubation Center [32] of NUST in Pakistan is an example of university business incubators which can facilitate university graduates to develop their innovative business ideas and transition into forming enterprises. Engineers having a sense of social responsibility are needed - who are committed to work towards alleviating poverty and empowering the underprivileged. This requires a unique worldview for being an engineer that a student is unlikely to develop through the traditional engineering education. Alternate educational models such as service learning [33] has the potential to allow students to develop competencies such as communication, working in cross-disciplinary teams and ethics which are required to work on the engineering projects of solving sociotechnical problems. Engineering educators need a change of perspective for education if future engineers are to be educated who are prepared to work within the local and global social complexities with a sense of professional responsibility of addressing human needs while taking into account the broader sustainability [34, 35].

\subsection{Challenges with Quality Assurance of Education}

The increasing importance of higher education, including engineering education, for the development of societies has led to the proliferation of higher education institutions in both developed and developing countries. Quality of education becomes a particular concern with the emergence of for-profit educational institutions many of which have an interest little more than credentialing their paying customers [26]. Governments in developing countries are establishing accreditation procedures to regulate the quality of education. Pakistan government in the last decade adopted several measures of educational reforms. Part of these reforms has been evaluating the quality of higher education in the country [36]. Higher Education Commission, as an organization of the federal government of Pakistan, engages with the higher education institutions of the country with the goal of facilitating them to develop capacity for quality assurance and enhancement. Besides a set of minimum requirements the general strategy is to promote self-assessment as a systematic and documented process in all the institutions of higher education in the country [37, 38]. Pakistan Engineering Council, mandated to regulate profession and education of engineering in the country, has adopted criteria for accrediting engineering programs that account for and relate with the accreditation procedures of HEC [39].

Efforts like these of instituting assessment and accreditation procedures are a relatively new phenomenon in many developing countries [40]. The stakeholders including governmental organizations and higher education institutions are going through a learning process of how to make quality assurance a sustained, viable and integrated process of higher education that could lead to continuous improvement [36]. A tension exists between governments adopting standardized criteria and objective assessment to regulate ill-intentioned educational programs and institutions attempting to experiment with innovative directions of developing education with their own vision. Stakeholders are making a sense of working in collaboration in a new paradigm of ongoing program assessment and accreditation so as to make it meaningful and worthwhile for everyone [41]. By focusing on improving the quality of education the hope is to graduate engineers who are more competent intellectually and professionally and are more aware and responsible as citizens. Such a vision requires policymakers to adopt quality assessment as a strategy not just because 'everyone is doing it' [42]. Policymakers need to be conscious of their assessment approaches acting as catalyst rather than an impediment for the development of 
education while having recognition of the complexity and diversity of higher education institutions.

Quality education is critical for the development of human capital having skills and moral values to make them a productive human resource for the economic growth of developing countries in today's globalized world. Educating competent and globally competitive engineering graduates has benefits not only if they work in the same country but those moving abroad for better opportunities develop a demand for higher education within the population of the country. Countries like Pakistan can best capitalize on such dynamics by ensuring quality of education for educating competent engineers. Being a globally competent engineer not only requires comprehensive technical knowledge in engineering but young graduates need to have strong communication skills and awareness of ethical responsibility which has become necessary in solving complex engineering problems in today's world. There is little attention in Pakistan for developing engineering education to incorporate communication and ethics in the education. Accreditation and quality assurance for engineering education lack criteria that require incorporating professional skills in education. This puts engineering graduates of the country at a significant disadvantage while competing with their global counterparts.

\subsection{Suggestions to Meet the Challenges}

One of the critical issues in the developing countries is the lack of student engagement in the learning process. Students are neither required to do independent learning through self-study nor are obliged to proactively work in groups to solve problems. This causes a number of issues including the lack of confidence in the students regarding the concepts learned, an inability to challenge ideas or think creatively, poor communication skills, lack of teamwork skills and inability to work in diverse environments. Part of the learning process is to question what one learns in terms of how it came about, how to implement it, how to improve it, etc. A student can be engaged in this process by integration of projects in the class or by having problem-based learning competitions. These competitions can be done in groups so students become keen for self-studying and for improving their designs and collaborating in their group. This at the same time will help develop teamwork skills. A number of books have been written on Project Based Learning (PBL) that can be used as tools to guide this activity - along with plethora of internet based resources.

With the rapid population increase in the developing countries, compared to developed countries, it can be expected that the majority of the engineering needs would have to be fulfilled by engineers educated in the developing countries. One of the ways to address challenges in graduating well-prepared engineers in the developing countries is by partnering with industries. A number of benefits can be achieved by this potential conglomeration. For instance, it would engage the students by helping them integrate knowledge and theory learned in class with practical applications and skills development in a professional setting. For this to be effective, students should be required to do internships/co-ops as part of their education as it provides an opportunity to acquire real world experience (hands-on education) on engineering problems and their solutions. It provides a quality exposure to the students in the field and provides insight into solving problems creatively and working in team environments. Students are better prepared for 
the future when they work in multidisciplinary teams and have the opportunity to network with other engineers to learn the global engineering trends.

Another advantage of partnering with industry is that the universities would be able to incorporate the input from industry to help improve the curriculum. The practical knowledge will hence educate engineers to solve the current problems faced in the country. This would aid in restructuring the curriculum to incorporate practical and applied perspectives and would prepare the graduating engineers to be ready to solve current problems while learning the basic foundations of engineering. When the industry recognizes the impact of their contribution, they would also be willing to contribute towards improving the resources of the universities. The contributions could be in terms of financial, technical, or human resources. This academiaindustry collaboration will help improve the learning facilities and tools available to educate the future engineers.

Another challenge is to educate the engineering educators. There are several ways this could be achieved. One mode is to have workshops in different parts of the developing countries to share effective ways of teaching and engaging students. Furthermore, networking opportunities could be developed between engineering educators from developed and developing countries. This would further enhance engineering educator's ability to share the effective use of technology to aid in the learning process. These workshops could also be used to highlight the importance of having well-prepared engineering graduates who could compete in the global market, be leaders, and solve the problems of the current and next generations. Another way to improve teacher effectiveness is to partner with leading universities across the world to discuss strategies on becoming effective facilitators in the student-learning process.

In terms of the trends and methodologies a major challenge that the universities in the developing countries face is the lack of computing resources. This could be addressed by partnering with industry, making a case to the educational boards in the respective countries, and by partnering with developed countries to help build the computing infrastructure as part of collaboration on educating well-prepared engineers. For the technical assistance, undergraduate students could be trained on troubleshooting issues and compensated by reduction of tuition fees or by tuition waiver programs. With any technology improvement, an investment in time would be needed to integrate it into teaching. Faculty would need to be provided adequate training on how to do it effectively. They could be compensated with summer pay or reduced course loads every few semesters.

The importance of communication, ethics and accreditation would become visible in developing countries when the industry collaborates with the educational institutions. Students in cooperative and internship programs would engage on real world problems and get a chance to work in multidisciplinary groups. They would enhance their communication and ethical skills, initially learned in the classroom. With industry imparting a certain level of education to the graduating engineers, the accreditation of the programs will become easier. 


\subsection{Conclusions}

In this paper, authors have discussed the various challenges in educating engineering students in developing countries and have identified potential areas of improvement. Challenges of effective teaching and learning and challenges with technology in developing countries are highlighted. Given the exploding population of the developing world, it can be expected that the majority of the engineers will be trained there. It is of paramount importance that effective engineering education processes are developed and implemented. This will ensure a global supply of wellprepared engineering graduates that can enhance focus on innovation, entrepreneurship and job creation and fulfill the shortage of quality engineers. Currently the developing countries face several challenges including lack of student-teacher interactive activities, inflexible curriculum to accommodate social and leadership skills, limited resources, and shortage of trained teachers. The higher education is also lagging behind in capitalizing on the dynamic electronic and computer revolution. Enough emphasis is not placed in higher education on communication, ethical values, and accreditation; these are important for a program to compete in a global market. Several suggestions and recommendations are presented based on new trends and methodologies to meet the challenges in Pakistani engineering institutions. These include the use of Project Based Learning (PBL) techniques, incorporating hands-on education, promoting internships and cooperative opportunities, conducting workshops, seminars and short courses, establishing collaborations with leading educational institutions across the world, and the use of online educational resources, amongst several others. Their corresponding benefits in terms of solving the large scale real world problems are also highlighted.

\section{References}

1. Marjoram T., Engineering shortage a threat to development, underlines UNESCO's first global report on engineering. Basic and Engineering Sciences, Natural Sciences, UNESCO Press, France, October 2010.

2. Morell L., Borri C., Rajala S. A. et al, IFEES: Enhancing Engineering Education at a Global Scale. Revista de Ensino de Engenharia (ABENGE), Vol. 27 N. 3, ISSN 0101-5001, 2008.

3. Kulacki F. A., and Krueger E .R., Trends in Engineering Education-An International Perspective. http://www.ineer.org/Events/ICEE1998/Icee/papers/508.pdf

4. National Academy of Engineering. The Engineer of 2020: Visions of Engineering in the New Century. Washington, DC: National Academies Press; 2004.

5. Qazi, S., Khalid. A., and Malik, Q., Incorporating New Trends and Teaching Methodologies: Improving State of Engineering Education in Pakistan. Proceeding of ASEE Annual Conference, Atlanta, GA, June 2013.

6. http://www.pec.org.pk/

7. Skinner, E. A., and Belmont, M. J., Motivation in the class room: Reciprocal effects of teacher behavior and student behavior across the school year. Journal of Education Psychology, 85(4), 1993

8. Kuh, G. D., Cruce, T. M., Shoup, R., Kinzie, J., and Gonyea, R. M., Unmasking the Effects of Student Engagement on First-Year College Grades and Persistence. The Journal of Higher Education, Vol. 79, No. 5 (Sep. - Oct., 2008), pp. 540-563

9. Handbook of Research on Student Engagement. Ed. Christenson, S. L., Reschly, A. L. and Wylie, C., Springer 2012

10. Pike, G. R. and Kuh, G. D., A typology of student of student engagement for American colleges and universities. Research in Higher Education, Vol. 46, No. 2, March 2005 
11. http://www.whitehouse.gov/sites/default/files/microsites/ostp/pcast-stemed-report.pdf

12. Gardner, J. F., Moll, A. J., and Pike, P. A., Active Learning in Mathematics: Using the Supplemental Instruction Model to Improve Student Success. Proceedings of the 2005 American Society for Engineering Education Annual Conference \& Exposition

13. Hodara, M., 'Improving Students' College Math Readiness: A Review of Evidence. Education Northwest, October 2013, http://educationnorthwest.org/webfm_send/1446

14. National Research Council. (2011). Successful K-12 STEM Education: Identifying Effective Approaches in Science, Technology, Engineering, and Mathematics. Committee on Highly Successful Science Programs for K-12 Science Education. Board on Science Education and Board on Testing and Assessment, Division of Behavioral and Social Sciences and Education. Washington, DC: The National Academies Press

15. Winnett, D., Four Challenges Classroom Teachers Face When They Integrate Technology into Their Teaching, Preparing Technology-Proficient Educators in Illinois. U.S. Department of Education, Southern Illinois University, Edwardsville, IL. June 2003

16. Morehead, P., LaBeau, Barbara, The Continuing Challenges of Technology Integration for Teachers, Essays in Education. Department of Education, University of South Carolina, ISSN: 1527-9359, Vol. 15, Sep 2005

17. Duderstadt J. J. Engineering for a Changing World: A Roadmap to the Future of American Engineering Practice, Research, and Education. In: Grasso D, Burkins MB, eds. Holistic Engineering Education. New York, NY: Springer; 2010:17-35.

18. ABET Engineering Accreditation Commission. Criteria for Accrediting Engineering Programs: Effective for Reviews during the 2013-2014 Accreditation Cycle. Baltimore, MD: ABET; 2012.

19. Wisnioski M. H. "Liberal Education Has Failed": Reading Like an Engineer in 1960s America. Technol Cult. 2009;50(4):753-782. doi:10.1353/tech.0.0346.

20. Leydens J. A. Sociotechnical Communication in Engineering: An Exploration and Unveiling of Common Myths. Eng. Stud. 2012;4(1):1-9. doi:10.1080/19378629.2012.662851.

21. Traver C., Klein J. D., Mikic B., et al. Fostering Innovation and Entrepreneurship through the Integration of Engineering and Liberal Education. Presented at the ASEE Annual Conference \& Exposition, Vancouver, BC, Canada: American Society for Engineering Education; 2011.

22. Khalid A., Chin C. A., Atiqullah M. M., Sweigart J. F., Stutzmann B., and Zhou W. Building a Better Engineer: The Importance of Humanities in Engineering Curriculum. Presented at the ASEE Annual Conference \& Exposition, Atlanta, GA: American Society for Engineering Education; 2013.

23. Dabipi I. K., Dodoo J. N. D., Burrows-McElwain J. B., and Hartman C. Adapting Engineering Education Curriculum for Global Competiveness in Developing Countries. Presented at the IEEE Transforming Engineering Education: Creating Interdisciplinary Skills for Complex Global Environments, Dublin, Ireland; 2010:1-8. doi:10.1109/TEE.2010.5508878.

24. Altbach P. G. Patterns of Higher Education Development. In: Altbach PG, Gumport PJ, Berdahl RO, eds. American Higher Education in the Twenty-First Century: Social, Political, and Economic Challenges. $3^{\text {rd }}$ ed. Baltimore, MD: Johns Hopkins University Press; 2011:15-36.

25. Lattuca L. R. Curricula in International Perspective. In: Forest JJF, Altbach PG, eds. International Handbook of Higher Education.Vol 18. Dordrecht, Netherlands: Springer; 2007:39-64.

26. Bloom D. E., and Rosovsky H. Higher Education in Developing Countries. In: Forest J. J. F., Altbach P. G., eds. International Handbook of Higher Education.Vol 18. Dordrecht, Netherlands: Springer; 2007:443459.

27. Altbach P. G., and Knight J. The Internationalization of Higher Education: Motivations and Realities. J Stud Int Educ. 2007;11(3-4):290-305. doi:10.1177/1028315307303542.

28. Bennell P., and Pearce T. The Internationalisation of Higher Education: Exporting Education to Developing and Transitional Economies. Int J Educ Dev. 2003;23(2):215-232. doi:10.1016/S0738-0593(02)00024-X.

29. Schofer E., and Meyer J. W. The Worldwide Expansion of Higher Education in the Twentieth Century. Am Sociol Rev. 2005; 70(6): 898-920. doi:10.1177/000312240507000602.

30. Li J., and Lin J. China's Move to Mass Higher Education: An Analysis of Policy Making from a Rational Framework. In: Baker D, Wiseman AW, eds. The Worldwide Transformation of Higher Education.Vol 9. Bingley, UK: JAI Press; 2008:269-295.

31. Amadei B. Engineering for the Developing World. The Bridge. 2004;34(2):24-31.

32. Technology Incubation Centre (TIC), National University of Sciences and Technology, Pakistan: http://www.nust.edu.pk/institutions/directortes/tic 
33. Coyle E. J, Jamieson L. H., and Oakes W. C. EPICS: Engineering Projects in Community Service. Int J Eng Educ. 2005;21(1):139-150.

34. Zandvoort H. Preparing Engineers for Social Responsibility. Eur J Eng Educ. 2008;33(2):133-140. doi:10.1080/03043790802024082.

35. Amadei B., and Sandekian R. Model of Integrating Humanitarian Development into Engineering Education. J Prof Issues Eng Educ Pract. 2010;136(2):84-92. doi:10.1061/(ASCE)EI.1943-5541.0000009.

36. Khwaja A. A., Zafar F., Aslam T., and Hussain A. Quality Assurance and Accreditation Practices in Pakistan. Islamabad, Pakistan: Quality Assurance Agency, Higher Education Commission; 2009.

37. Batool Z., Qureshi R. H., and Raouf A.. Performance Evaluation Standards for the HEIs. Islamabad, Pakistan: Higher Education Commission; 2010.

38. Batool Z., and Qureshi R. H. Quality Assurance Manual for Higher Education in Pakistan. Islamabad, Pakistan: Higher Education Commission, 2008.

39. Engineering Accreditation and Quality Evaluation Committee. Manual of Accreditation. Islamabad, Pakistan: Pakistan Engineering Council; 2007.

40. Almusallam A. Accreditation and Quality Assurance in Higher Education in the Kingdom of Saudi Arabia. Riyadh, Saudi Arabia: National Commission for Academic Accreditation \&Assessment; 2009.

41. Hussain, T. Integrating PEC'S Accreditation Criteria and HEC'S Self-Assessment Criteria for Improving Quality in Higher Education. Presented at the $3^{\text {rd }}$ International Conference on Assessing Quality in Higher Education, Lahore, Pakistan; 2010.

42. Lao R. The Noodle Bowl Effect in Our Higher Education System. Bangkok Post. http://www.bangkokpost.com/opinion/opinion/384176/the-noodle-bowl-effect-in-our-higher-educationsystem. Published December 11, 2013. 